Original Article

\title{
Assessment of treatment pattern of childhood asthma reporting to outpatients' facility of a tertiary care hospital in Lucknow, North India: A cross-sectional study
}

\author{
Sarika Gupta ${ }^{a,}$, , Shally Awasthi ${ }^{b}$ \\ ${ }^{a}$ Assistant Professor, Department of Pediatrics, KGMU, Lucknow, India \\ ${ }^{\mathrm{b}}$ Professor, Department of Pediatrics, KGMU, Lucknow, India
}

\section{A R T I C L E I N F O}

\section{Article history:}

Received 24 June 2016

Accepted 28 August 2016

Available online 30 September 2016

Keywords:

Asthma

Treatment

Guidelines

Children

Severity

\begin{abstract}
A B S T R A C T
Problem considered: Global initiative for Asthma (GINA) guidelines recommend a stepwise approach to instituting and adjusting therapy for children with asthma. The objective of this study was to describe the physicians prescribing patterns of childhood asthma, in accordance with GINA guidelines.

Methods: This hospital-based, cross-sectional study was conducted after institutional ethical clearance. Children aged 1-12 years with asthma were recruited after parental consent from the outpatients' department (OPD). Drugs used for the treatment of acute exacerbation of asthma and for long-term control of asthma were assessed as per the GINA 2009 guidelines. Qualification together with identity of treating physician was kept anonymous.

Results: From August 2008 to August 2011, 250 children were recruited. Out of them, 35.2\% had mild intermittent, $37.2 \%$ had mild persistent, $20 \%$ had moderate persistent and $7.6 \%$ had severe persistent asthma. There were $94.4 \%$ children with acute exacerbation of asthma. For the management of current episode of acute exacerbation of asthma, SABA through oral route $(77.3 \%)$ was preferred over inhalation (22.7\%). Antibiotics $(53.4 \%)$ and antitussives (52.1\%) were prescribed in considerable proportions of exacerbations. The prescription pattern of controller drugs was not in line with the GINA guidelines, as it did not vary much across asthma severity categories. As compared to intermittent asthma, children with persistent asthma were prescribed as and when required salbutamol more $(\mathrm{OR}=2.5 ; 95 \%$ $\mathrm{CI}=1.15-5.51 ; p=0.018$ ). None of the prescriptions have any documentation of evaluation of either severity of asthma or level of control of asthma.

Conclusion: Prescription pattern of drugs for asthma exacerbation and long-term control do not correspond to GINA guidelines recommendations. Operative strategies aimed at implementing existing guidelines into daily practice are urgently needed.

(C) 2016 INDIACLEN. Published by Elsevier, a division of RELX India, Pvt. Ltd. All rights
\end{abstract} reserved.

\footnotetext{
* Corresponding author at: B-34, Sector L, LDA, Bangla Bazar, Lucknow 12, India.

E-mail address: sgguptasarika@gmail.com (S. Gupta). 


\section{Introduction}

Asthma is one of the common reasons for children's visits to emergency departments (EDs). ${ }^{1}$ Studies have shown that the care and management of asthma in children are markedly short of goals set in the GINA guidelines for asthma management. ${ }^{2,3,4}$

Identifying the causes of suboptimal control is necessary in order to improve asthma care. Suboptimal management by physicians was a likely cause of significant asthma morbidity worldwide. ${ }^{5,6,7,8,9}$ Yet, data on this aspect of asthma care are limited.

There is a recent trend of increasing pediatric asthma cases. ${ }^{9}$ Since the economic cost of asthma has been found to be considerable, it is essential that some assessment must be done upon the management of these patients to ensure more cost-effective management. It has been accepted that evidence-based clinical guidelines for the treatment of asthma ${ }^{2}$ and asthma education are the best methods available to allow patients to receive a high quality of care and better disease outcomes.

Therefore, in this study, we aimed to assess the treatment pattern of childhood asthma, as prescribed by the physicians in the Lucknow city, in accordance with GINA guidelines.

\section{Methods}

Study design: Hospital-based cross-sectional study.

Setting: This study was conducted in the outpatients' department (OPD) of Department of Paediatrics at King George's Medical University (KGMU), Lucknow, Uttar Pradesh, Global initiative for Asthma.

Participants: The children who present with the symptoms of bronchial asthma ${ }^{10}$ were recruited from the OPD. Included in the study were 250 children, aged 1-12 years, with the diagnosis of bronchial asthma.

Variables, data sources/measurement: The present study was approved by the KGMU ethics committee and written informed consent for participation was obtained from parents/ guardians of all recruited asthmatic children. Cases were children, aged 1 to 12 years, presenting with symptoms of bronchial asthma. Bronchial asthma for the present study was defined as the presence of one or more of the following symptoms: (i) current presence of wheeze in any child with a history of more than four episodes of documented wheeze or use of bronchodilators in the preceding 12 months, or (ii) relief with bronchodilators with or without short course oral steroid or on any regular medication for asthma, or (iii) currently hospitalized and diagnosed as case of bronchial asthma. ${ }^{10}$ Those children who had any other respiratory disease or with alternative causes of recurrent wheezing were excluded.

To assess disease severity, the 2002 GINA classification system which divides patients into four severity categories (mild intermittent, mild, moderate, and severe persistent asthma) based on frequency of day time and night symptoms was used. ${ }^{2}$ For the purpose of analysis, all subgroups of persistent asthma were merged together. Classification of asthma control was based on the 2009 GINA guidelines. ${ }^{2}$
Asthma was considered to be controlled when daytime symptoms are twice a week or less, no limitations of activities, no nocturnal symptoms or awakenings and need for reliever/ rescue treatment twice a week or less. Asthma was considered to be partly controlled if any of these measures were present in any week: daytime symptoms more than twice a week, any limitations of activities, any nocturnal symptoms or awakenings and need for reliever/rescue treatment more than twice a week. Asthma was considered to be uncontrolled if three or more features of partly controlled asthma was present in any week. A standardized data collection form was developed for the collection of data. Treatment patterns for acute exacerbation of asthma and for long term control of asthma were assessed as per the GINA 2009 guidelines. Qualification and identity of treating physician was kept anonymous.

Statistical analysis: EpiI6 (available from the centers for Disease control and Prevention; Atlanta, GA, USA; http://www. cdc.gov/epo/epi/epiinfo.htm) and SPSS 11.5 (Chicago, IL, USA) were used for statistical analysis. Each variable has been scanned for normalcy of distribution. Mean and SD were calculated for continuous variables and proportions were calculated for categorical variables. Chi-square test with $2^{\circ}$ of freedom was used for categorical variables and Student's t-test or ANOVA test was used for continuous variables. Fischer test was used where applicable. To assess the association between dependent and independent variables, odd's ratios were calculated with $95 \%$ confidence interval. Using a 2-tailed distribution, $p$-value of $<0.05$ was considered statistically significant.

\section{Results}

Included in the study were 250 children, aged 1-12 years diagnosed as bronchial asthma. Table 1 depicts the Baseline characteristics of recruited children. Out of the 250 children with asthma, 88 (35.2\%) had intermittent asthma and 162 (64.80\%) had persistent asthma. There were 236 (94.4\%) children with acute exacerbation of asthma and $14(5.6 \%)$ children in stable state. Asthma was controlled in $14(5.6 \%)$ children, partially controlled in 108 (43.2\%) children and uncontrolled in 128 (51.2\%) children.

Table 2 depicts the prescription pattern of drugs for management of current episode of acute exacerbation of asthma, prior to visit at KGMU. For the current episode multiple drugs (60.5\%) were given more often as compared to single drug (39.4\%). The short acting $\beta$ agonist (SABA) was prescribed through oral route (77.2\%) more than compared to inhaled route $22.8 \%$ Antibiotics were prescribed in 126 (53.4\%) children. Antitussives were prescribed in 123 (52.1\%) children.

Table 3 represents the prescription pattern of long-term controller drugs for asthma as prescribed by practitioners in Lucknow prior to visit at KGMU. Table 4 represent prescription pattern of long term controller drugs for asthma as prescribed by practitioners in Lucknow prior to visit at KGMU according to the level of severity. For the purpose of analysis all subgroups of persistent asthma were merged together. As compare to intermittent asthma (78.4\%), children with persistent asthma (90.1\%) were prescribed sos salbutamol more often and the difference was statistically significant 
Table 1 - Baseline characteristics of recruited children with asthma.

\begin{tabular}{ll} 
Characteristics & $\begin{array}{c}\text { Children with } \\
\text { asthma }(\mathrm{N}=250)\end{array}$ \\
\hline Age (months) at recruitment (mean $\pm \mathrm{SD})$ & $75.42 \pm 39.79$ \\
Age (months) at onset (mean $\pm \mathrm{SD})$ & $31.70 \pm 33.48$ \\
Male; $n$ (\%) & $160(64.0 \%)$ \\
Total socioeconomic status; $n$ (\%) & $129(51.6 \%)$ \\
Upper & $121(48.4 \%)$ \\
Lower & $145(58.0 \%)$ \\
Urban residence; $n(\%)$ & $17.90 \pm 7.28$ \\
Weight $(\mathrm{kg})$ (mean $\pm \mathrm{SD})$ & $110.47 \pm 20.59$ \\
Height $(\mathrm{cm})$ (mean $\pm \mathrm{SD})$ & $14.04 \pm 2.15$ \\
BMI (kg/m ${ }^{2}$ ) (mean $\left.\pm \mathrm{SD}\right)$ & \\
Asthma severity & $88(35.2 \%)$ \\
Intermittent & $162(64.8 \%)$ \\
Persistent & $14(5.6 \%)$ \\
Level of control of asthma & $108(43.2 \%)$ \\
Controlled & $128(51.2 \%)$ \\
Partly controlled & \\
Uncontrolled & $14(5.6 \%)$ \\
Type of case & $236(94.4 \%)$ \\
Stable & $168(67.2 \%)$ \\
Acute exacerbation & $6.16 \pm 3.94$ \\
Any previous hospitalization; $n(\%)$ & \\
Number of visit to doctors in & $7.53 \pm 7.26$ \\
last 1 year, mean \pm SD & \\
Number of school days missed & \\
for the present episode, mean $\pm \mathrm{SD}$ & \\
\hline BMI $=$ body mass index. & \\
\hline
\end{tabular}

$(\mathrm{OR}=2.5 ; 95 \% \mathrm{CI}=1.15-5.51 ; p=0.018)$. There was no statistically significant difference among the intermittent and persistent asthma in reference to prescription of any controller drugs including ICS, LTRA and ICS plus LTRA combination.

The median duration of use of long-term controller drugs for asthma in months (mean $\pm \mathrm{SD}$ ) was $2.93 \pm 1.54$ for intermittent asthma and $2.90 \pm 1.63$ for persistent asthma. The difference in the duration of use of controller medicines as per the severity of asthma was not statistically significant.
Table 3 - Prescription pattern of long-term controller drugs, prior to visit at KGMU.

\section{Characteristics}

Children with asthma $(N=250)$

Documented use of any

controller drugs; $\mathrm{N}(\%)$

ICS; $n(\%)$

LTRA; $n(\%)$

ICS + LTRA; $n(\%)$

ICS + LABA; $n(\%)$

ICS + LABA + LTRA + Theophylline; $n(\%)$

Duration of use of controller

$$
\text { drugs (mean } \pm \mathrm{SD} \text { ) }
$$

ICS = inhaled corticosteroids; LTRA = leukotriene receptor antagonist; LABA = long acting $\beta$ agonist.

\section{Discussion}

This study was conducted with the objective of doing assessment of the treatment pattern of childhood asthma, as prescribed by the physicians in the Lucknow city, in accordance with GINA guidelines.

For management of acute exacerbation of asthma, GINA guidelines recommend use of inhaled SABA, inhaled ipratropium, and corticosteroids as initial drugs, sequentially in combination. In the study $60.5 \%$ children were on multiple drug therapy compared to $39.4 \%$ children on single drug therapy. Previous studies have reported use of multiple drugs in $80-90 \%$ patients and use of single drug in only $10-20 \%$ patients. ${ }^{11,12}$

SABA was the most frequently (87.6\%) used drug for management of acute exacerbation including prescription as monotherapy and in combination followed by ipratropium and corticosteroids. For acute exacerbation of asthma, the use of SABA had been reported by various authors in the range of $45-70.4 \%{ }^{11,12,13,14,15,16,18}$ Use of emergency steroids were reported to $30.6 \%$ of children. ${ }^{12}$ Another study reported that

Table 2 - Prescription pattern of drugs for management of current episode of acute exacerbation of asthma, prior to visit at KGMU.

Characteristics
Children presenting with asthma exacerbation $(N=236)$
Single drug therapy; $N(\%)$

Documented use of $\beta-2$ agonist for current episode as monotherapy; $n(\%)$

Documented use of ipratropium for current episode as monotherapy; $n(\%)$

Documented use of systemic steroid for current episode as monotherapy; $n$ (\%)

Multiple drug therapy; $N(\%)$

Documented use of $\beta-2$ agonist and systemic steroid for current episode; $n$ (\%)

Documented use of $\beta-2$ agonist and ipratropium for current episode; $n(\%)$

Documented use of $\beta-2$ agonist, ipratropium and systemic steroid for current episode; $n$ (\%)

Route of administration of $\beta$-2 agonist

Inhaled route; $n(\%)$

Oral route; $n(\%)$

Route of administration of systemic steroid

Injectable route; $n(\%)$

Oral route; $n(\%)$
$93(39.4 \%)$

$64(27.1 \%)$

$9(3.8 \%)$

$20(8.5 \%)$

$143(60.5 \%)$

$52(22.0 \%)$

$53(22.4 \%)$

38 (16.1\%)

47 (22.7\%)

$160(77.3 \%)$

$16(14.6 \%)$ $94(85.4 \%)$

ICS = inhaled corticosteroids; LTRA = leukotriene receptor antagonist; LABA = long acting $\beta$ agonist. 
Table 4 - Prescription pattern of long term controller drugs according to the level of severity of asthma.

\begin{tabular}{|c|c|c|c|c|c|}
\hline Characteristics & $\begin{array}{l}\text { Mild intermittent } \\
\text { asthma } \\
N=88\end{array}$ & $\begin{array}{l}\text { Mild persistent } \\
\text { asthma } \\
\text { N }=93\end{array}$ & $\begin{array}{c}\text { Moderate persistent } \\
\text { asthma } \\
\mathrm{N}=50\end{array}$ & $\begin{array}{c}\text { Severe persistent } \\
\text { asthma } \\
N=19\end{array}$ & $p$ value \\
\hline Salbutamol sos & $69(78.4 \%)$ & $82(88.2 \%)$ & $47(94.0 \%)$ & 4 (78.9\%) & 0.056 \\
\hline $\begin{array}{l}\text { Documented use of any } \\
\text { controller drugs; } n(\%)\end{array}$ & $54(61.4 \%)$ & $66(71.0 \%)$ & 39 (78.0\%) & $12(63.2 \%)$ & 0.188 \\
\hline ICS; $n(\%)$ & $38(43.2 \%)$ & $40(43.0 \%)$ & $11(22.0 \%)$ & $2(10.5 \%)$ & 0.003 \\
\hline LTRA; $n(\%)$ & $7(8.0 \%)$ & $10(10.8 \%)$ & $7(14.0 \%)$ & $2(10.5 \%)$ & 0.750 \\
\hline ICS + LTRA; $n(\%)$ & $9(10.2 \%)$ & $8(8.6 \%)$ & 7 (14.0\%) & $5(26.3 \%)$ & 0.148 \\
\hline ICS + LABA; $n(\%)$ & - & $4(4.3 \%)$ & $5(10.0 \%)$ & $1(5.3 \%)$ & 0.040 \\
\hline ICS + LABA + LTRA + Theophylline; $n(\%)$ & - & $4(4.3 \%)$ & $9(18.0 \%)$ & $2(10.5 \%)$ & $<0.00$ \\
\hline
\end{tabular}

$78.5 \%$ of children were discharged from the ED on a short course of oral corticosteroids. ${ }^{13}$ Documented use of ipratropium for current episode as monotherapy was reported in $3.8 \%$ of children. It seems very unusual that that some physician had prescribed it alone for acute exacerbation of asthma. It may be possible that the concerned physician added it over and above the other drugs prescribed by some other physician to whom the children had visited earlier.

SABA in combination with systemic corticosteroids or with iptatropium could be capable of functioning like the two most commonly prescribed dual-agent combined therapies. Previous studies had reported that corticosteroid combined with beta2-agonist, followed by beta2-agonist combined with a xanthine derivative were the two most commonly prescribed dual-agent combined therapies by physicians. ${ }^{14,15}$

For administration of SABA, oral dosage forms were preferred over inhalation. Previous studies also document preference of oral route over the inhaled route for the administration of SABA for management of acute exacerbation of asthma. Pandey et al. demonstrated that oral dosage form (56.3\%) was preferred over inhalation (33.8\%). ${ }^{11}$ Srivastava et al. reported that, oral dosage form like tablets (54.93\%) was preferred over inhalation (31.69\%). ${ }^{9}$ On the physicians side, it might be because the physicians do not feel confident in prescribing the inhaler therapy. On the patient's side, the level of acceptance may be low due to non-compliance and lack of coordination associated with use of inhaler. This issue can be ameliorated by more of patient's education and convincing by the treating physician for inhalational therapy.

The doses of asthma medications for acute exacerbation of asthma were not documented in any prescription. Such lacunae in the prescription of acute exacerbation of asthma have been documented by other authors. Previous studies have reported ${ }^{12}$ that the doses of asthma medications were not documented in $37.3 \%$ of cases. It suggests that in our setting, we need to encourage the physicians to prescribe the doses of asthma medications.

Antibiotics (53.4\%) and antitussives (52.1\%) were prescribed in considerable proportions of exacerbations. However, the data on type of antibiotics and composition of antitussives were not documented. The antibiotic use for wheezing in children had decreased over the years, but still it is prescribed by the practitioners in about $23-64 \%$ of children. ${ }^{17}$ This issue needs to be addressed through proper educational training of physicians, as it has implications for antibiotic resistance.
Other researchers had documented prescription of antitussives in asthmatic children 2536 times (mean 12.3). ${ }^{12}$

It states that for the management of acute exacerbation of asthma, the physicians in Lucknow followed the GINA guidelines in a fairly enough way; however, certain lacunae have been noted.

Short-acting bronchodilators are recommended for relief of mild intermittent asthma and it should always be available as needed for children with persistent asthma who are using regular controller therapy As compared to intermittent asthma, children with persistent asthma were prescribed as and when required salbutamol more $(\mathrm{OR}=2.5 ; 95 \% \mathrm{CI}=1.15-$ $5.51 ; p=0.018)$. It point to more uncontrolled disease. This may be due to inadequate use of long-term controller drugs in persistent asthma. There are a number of studies and reviews which emphasize that early intervention with controller drugs provides significant clinical improvement at a savings in both direct and indirect costs. ${ }^{13,14,15,16}$

Use of long-term controller medicines was reported by $68.4 \%$ of children. Previous studies indicates that long-term controller medicines prescription ranges from $35.4 \%^{11}$ to $60 \%{ }^{17,20}$ ICS as a monotherapy was prescribed to $53.2 \%$ of children. As reported the prescription rate for ICS monotherapy as $7.8 \%$ by pediatricians, $5.6 \%$ by family physicians, and $8.0 \%$ by other physicians. ${ }^{19}$

According to the GINA guidelines, for the long-term control of asthma mild intermittent asthma, no daily medication is needed. They require need bases reliever medicines only. However controller drugs were prescribed in almost similar proportions for patients with intermittent asthma (61.4\%) as for those with persistent asthma (72.2\%) [CI = 0.91-2.94]. It may be due to inappropriate prescription or it may also be possible that such children required SABA more than two times per week, which indicate the need to start long-term control medication.

For mild persistent asthma, GINA guidelines recommend one daily long-term control medication with ICS as preferred therapy over LTRA or theophylline derivatives. Only $71 \%$ of children with mild persistent asthma were prescribed long term controller therapy, of which ICS was prescribed to $43 \%$ of children only. Rest of the $28 \%$ children with mild persistent asthma were prescribed ICS either in combination with additional long-term controller drugs (17.2\%) or LTRA alone $(10.8 \%)$. None of the children were prescribed theophylline derivatives. 
For moderate persistent asthma, GINA guidelines recommend ICS with or without additional long-term controller drugs. About $78 \%$ of children were prescribed long-term controller therapy. However combination therapy with ICS and other long-term controller drugs was prescribed to $42 \%$ children only, rest were prescribed ICS or LTRA as monotherapy.

For severe persistent asthma, multiple long-term control drugs have been recommended with, if needed, oral corticosteroids. However the prescriptions revealed that long-term controller therapy was prescribed to $63 \%$ of children only, with multiple long-term controller drugs to $10 \%$ of children only. None of them were prescribed oral corticosteroids.

It concluded that the prescription pattern of controller drugs as per the severity of asthma was not in line with the GINA guidelines as it did not vary much across asthma severity categories. The pattern of prescription of ICS, which GINA guidelines recommend for children with mild or moderate or severe persistent asthma, was further evidence that recalled asthma severity and therapy were not consistent. The pattern of prescription of LTRA alone or in combination with ICS was nearly similar across the severity of asthma. It was contrary to GINA guidelines which recommend use of LTRA mainly for mild persistent asthma. GINA guidelines recommend combination therapy with ICS and LABA, for patients with moderate or severe persistent asthma. However combination ICS + LABA therapy were prescribed to about $8 \%$ of children with mild persistent asthma. A study had reported that combination therapy with ICS-LABA therapy was prescribed for $7 \%$ of patients; in that, most of whom were classified as having intermittent or mild persistent asthma. ${ }^{28}$

Our findings point to sub-optimal clinical practice, but similar findings have been reported earlier also in India as well as globally. ${ }^{25,26,27,28}$ A study documented adherence to guidelines concerning diagnosis and frequency of follow-up for Danish asthmatic schoolchildren in $7 \%$ of the cases only. Though care by hospital specialists was more in concordance with guidelines as compared to general practitioners, all the standards of care as per guidelines were not met by majority of hospital specialists. ${ }^{28}$ Recent documentation from western countries highlighted the poor alignment of maintenance therapy with the recommendations of asthma guidelines. $^{29,30}$

Many reasons have been proposed for the failure to follow guidelines, including low efficiency of inhalation, inadequate drug delivery, low adherence, insufficient monitoring and follow-up, incomplete dissemination, lack of agreement, time pressures, lack of self-efficacy, and inertia of prior practice. $^{22,28}$

None of the prescriptions have any documentation of evaluation of either severity of asthma or level of control of asthma. Since the administration of long-term controller therapy requires appropriate asthma severity and level of control classification, the encouragement of physicians to include asthma severity classification as a part of routine evaluation may help physicians to address controller medications in uncontrolled asthma. Long-term treatment is generally required for an effective management. Poor asthma control has previously been attributed to underestimation of severity by the physician and lacks of prescription of long-term controller drugs especially the ICS. ${ }^{23}$ Though dearth of compliance and fear of steroids by parents may possibly also be reasons by some patients for not using the prescribed dose of steroids. It indicates an urgent need for improved patients and physicians education training as timely use of ICS reduces morbidity and mortality and improves outcomes for all severity levels of asthma. ${ }^{24}$

The sample size is one of the strengths of study. Care was taken to have a precise clinical definition of asthma. Weakness of our study is not only that the data on use of asthma equipment, use of peak flow meter or spirometer, and use of asthma action plan and but also that doses of drugs were not collected.

Thus we conclude that despite the availability and regular updates of guidelines for asthma pharmacotherapy, inappropriate use of asthma medications persists (specifically excessive use of oral SABA combined with underuse of controller drugs). This is a direct evidence for suboptimal asthma control in children, with long-term management falling far short of the goals set in the GINA guidelines.

These findings suggest that operative strategies aimed at implementing existing GINA guidelines into daily practice are urgently needed. Hence there is a need to encourage physicians of Lucknow to ensure the effective management of asthma as per the GINA guidelines which emphasizes a partnership between the physician and family of the child resulting in the achievement of control by self-management under the guidance of the physician. These include increasing the use of current asthma management guidelines by practitioners, improving documentation of prescribed medications and their dosage and improving education of parents in home management measures.

To overcome the factors contributing to non-adherence to pediatric asthma guidelines, certain solutions have been suggested globally. ${ }^{31}$ The most important one is awareness of barriers that pediatricians often face while using guidelines and interventions tailored as per the barrier. It had been documented that studies on improving physician's adherence to guideline may not be generalizable, since barriers in one setting may not be present in another. ${ }^{32}$ Effective means of knowledge transfer should be developed and implemented to improve the translation of guideline recommendations into care. ${ }^{33}$ This study may be helpful to improve the prescribing pattern of asthma through successful implementation of interventional program in the health care centers.

It is concluded that the present prescribing pattern of antiasthmatics in Lucknow does not completely meet standard GINA guidelines of asthma treatment. It includes preferential use of oral form of SABA over the inhalation, non-documentation of doses of asthma drugs, use of antibiotics and antitussives for acute exacerbation, non-documentation of severity and level of control of asthma and inadequate use of long-term controller drugs.

\section{Conflicts of interest}

The authors have none to declare. 


\section{Acknowledgement}

\author{
We are thankful to ICMR for funding the MD-PhD of Dr Sarika \\ Gupta.
}

\section{R E F E R E N C E S}

1. Akinbami LJ, Schoendorf KC. Trends in childhood asthma: prevalence, health care utilization, and mortality. Pediatrics. 2002;110:315-322.

2. Global Initiative for Asthma (GINA). Global strategy for asthma management and prevention. National Heart, Lung and Blood Institute. NIH Publication No 02-3659, National Institute of Health, GINA; 2009.

3. Lai CK, De Guia TS, Kim YY, et al. Asthma control in the Asia-Pacific region: the Asthma Insights and Reality in Asia-Pacific Study. J Allergy Clin Immunol. 2003;111: 263-268.

4. Rabe KF, Adachi M, Lai CK, et al. Worldwide severity and control of asthma in children and adults: the global asthma insights and reality surveys. J Allergy Clin Immunol. 2004;114:40-47

5. Wong B, Tan C, Lee BW, Van Bever HP, APARI Study Group. Monitoring and management of childhood asthma in Asian countries: a questionnaire study. World Allergy Organ J. 2009;2(January (1)):3-8.

6. Gautam VP, Shah A, Malhotra A, et al. General practitioners' knowledge of childhood asthma in Delhi, India. Int J Tuberc Lung Dis. 2008;12:677-682.

7. Bedi RS. Asthma management by private general practitioners of Punjab. Indian J Chest Dis Allied Sci. 1994;36: 9-13.

8. Yeh KW, Chiang LC, Chen SH, Huang JL. Survey of the clinical practice of physicians in the management of asthma in Taiwan. Asian Pac J Allergy Immunol. 2006;24:1-8.

9. Srivastava R, Sharma S, Keshri L, Wal P. Assessment of prescription pattern in asthma therapy at Shamli hospitals. Rev Recent Clin Trials. 2012;7(May (2)):158-164.

10. Awasthi S, Gupta S, Maurya N, Tripathi P, Dixit P, Sharma N. Environmental risk factors for persistent asthma in Lucknow. Indian J Pediatr. 2012;79(October (10)):1311-1317.

11. Pandey A, Tripathi P, Pandey RD. Prescription pattern in asthma therapy at Gorakhpur hospitals Lung India. 2010;27 (January-March (1)):8-10.

12. Dashash NA, Mukhtar SH. Prescribing for asthmatic children in primary care. Are we following guidelines? Saudi Med J. 2003;24:507-511.

13. Shih YC, Mauskopf J, Borker R. A cost-effectiveness analysis of first-line controller therapies for persistent asthma. Pharmacoeconomics. 2007;25:577-590.

14. Navarro RP, Parasuraman B. Cost effectiveness of asthma controller therapies: influence of disease severity and other variables. Manag Care Interface. 2005;18:31-40.

15. Weiss K, Buxton M, Andersson FL, Lamm CJ, Liljas B, Sullivan SD. Cost-effectiveness of early intervention with once-daily budesonide in children with mild persistent asthma: results from the START study. Pediatr Allergy Immunol. 2006;17(suppl 17):21-27.

16. Rodriguez-Martinez CE, Sossa-Briceño MP, Castro-Rodriguez JA. Cost-utility analysis of once-daily versus twice-daily inhaled corticosteroid dosing for maintenance treatment of asthma in pediatric patients. J Asthma. 2016;53:538-545.

17. Lovinsky S, Rastogi D. Prescription habits for preventative medications among pediatric emergency department physicians at an inner-city teaching hospital. J Asthma. 2010;47:1011-1014.

18. Asher MI, Montefort S, Bjorksten B, et al. Worldwide time trends in the prevalence of symptoms of asthma, allergic rhinoconjunctivitis, and eczema in childhood: ISAAC phases one and three repeat multicountry cross-sectional surveys. Lancet. 2006;2:733-743.

19. Sun HL, Kao YH, Chou MC, Lu TH, Lue KH. Differences in the prescription patterns of anti-asthmatic medications for children by pediatricians, family physicians and physicians of other specialties. J Formos Med Assoc. 2006;105:277-283.

20. Carlton BG, Lucas DO, Ellis EF, Conboy-Ellis K, Shoheiber O, Stempel DA. The status of asthma control and asthma prescribing practices in the United States: results of a large prospective asthma control survey of primary care practices. J Asthma. 2005;42:529-535.

22. Adams RJ, Fuhlbrigge A, Guilbert T, Lozano P, Martinez F. Inadequate use of asthma medication in the United States: results of the asthma in America national population survey. J Allergy Clin Immunol. 2002;110:58-64.

23. Wolfenden L, Diette G, Krishnan J, Skinner E, Steinwachs D, Wu A. Lower physician estimate of underlying asthma severity leads to undertreatment. Arch Intern Med. 2003;163:231-236

24. Suissa S, Ernst P. Inhaled corticosteroids: impact on asthma morbidity and mortality. J Allergy Clin Immunol. 2001;107: 937-944.

25. Cabana MD, Abu-Isa H, Thyne SM, Yawn B. Specialty differences in prescribing inhaled corticosteroids for children. Clin Pediatr. 2007;46:698-705.

26. Cabana MD, Rand CS, Becher OJ, Rubin HR. Reasons for pediatrician nonadherence to asthma guidelines. Arch Pediatr Adolesc Med. 2001;155:1057-1062.

27. Moth G, Schiotz PO, Vedsted P. A Danish population-based cohort study of newly diagnosed asthmatic children's care pathway - adherence to guidelines. BMC Health Serv Res. 2008;8:130. http://dx.doi.org/10.1186/1472-6963-8-130.

28. Thomas M, Murray-Thomas T, Fan T, Williams T, Taylor S. Prescribing patterns of asthma controller therapy for children in UK primary care: a cross-sectional observational study. BMC Pulm Med. 2010;10(May):29.

29. Casares-Alonso. Cano-Garcinuño. Blanco-Quirós. PérezGarcía Allergol. Anti-asthmatic prescription variability in children according to age. Immunopathol (Madr). 2015;43: 383-391.

30. Arellano FM, Arana A, Wentworth CE, Vidaurre CF, Chipps $B E$. Prescription patterns for asthma medications in children and adolescents with health care insurance in the United States. Pediatr Allergy Immunol. 2011;22:469-476.

31. Lamontagne AJ, Peláez S, Grad R, et al. Facilitators and solutions for practicing optimal guided asthma selfmanagement: the physician perspective. Can Respir J. 2013;20(July-August (4)):285-293.

32. Cabana MD, Rand CS, Powe NR, et al. Why don't physicians follow clinical practice guidelines? A framework for improvement. JAMA. 1999;20(282):1458-1465.

33. Klok T, Kaptein AA, Brand PL. Non-adherence in children with asthma reviewed: the need for improvement of asthma care and medical education. Pediatr Allergy Immunol. 2015;26 (3):197-205. 